\title{
Mitochondrial DNA Variation in Indigenous Sheep (Ovis aries) Breeds of Nepal
}

\author{
N.A. Gorkhali, J.L. $\operatorname{Han}^{1}$ and Y.H. Ma ${ }^{2 *}$ \\ Institute of Animal Science \\ Chinese Academy of Agricultural Sciences \\ Beijing, China
}

\begin{abstract}
Nepal borders India in the south and China in the north. Four distinct indigenous domestic sheep breeds, i.e. Bhyanglung in the alpine region, Baruwal in the high hills, Kage in the mid hills and Lampuchhre in the low lands are distributed in the country. In this study, the mitochondrial DNA control region of 111 sheep from these four breeds was directly sequenced to determine their genetic variations and phylogenetic relationships. High mitochondrial DNA diversity among these breeds was observed and all haplotypes were classified into three haplogroups (A to C). Among the four breeds, three residing in middle to high hills had all three haplogroups while Lampuchhre sheep in low land only carried haplogroups $A$ and $B$. This study revealed that a south-western route of gene flow in sheep might have come from China to India via Nepal. It can be concluded that these indigenous sheep breeds have isolated breeding paths. Lack of crossbreeding among Nepalese sheep breeds is unique, and it is important for the decision making on utilization and conservation of Nepalese sheep genetic resources.
\end{abstract}

Keywords: Control region, mitochondrial DNA, Nepalese indigenous breed, sheep (Ovis aries)

\section{INTRODUCTION}

Domestic sheep (Ovis aries) have played a significant role in the economy of small and marginal farmers, especially in developing countries, as they are a potential source of meat, wool, milk, hide and manure. Even though Nepal is a small country with a territory of 147,181 square kilometres; it has a wide range of climates, mainly affected by different altitudes. Following the variations in agro-ecological zones and climates, Nepalese sheep have evolved into four different breeds: Bhyanglung in the alpine region (3000 masl to 5000 masl), Baruwal in the high hills (2000 masl to 3000 masl), Kage in the middle hills (600 masl to 1500 masl) and Lampuchhre in the low lands (sea level to 600 masl). These breeds are phenotypically distinct from each other (Neopane et al., 2008).

Diversity of mitochondrial DNA (mtDNA) has been widely used to assess the origin, phylogeny and population structure of sheep breeds all over the world (Hiendleder et al., 1998a, 1998b, 2002; Meadows et al., 2005, 2007; Pedrosa et al., 2005, 2007; Pereira et al., 2006; Tapio et al., 2006; Oner et al., 2013), specifically in China (Guo et al., 2005; Luo et al., 2005; Chen et al., 2006; Wang et al., 2007; Sulaiman et al., 2011; Zhao et al., 2011) and

\footnotetext{
Institute of Animal Science, Chinese Academy of Agricultural Sciences, Beijing 100193, China

Animal Breeding Division, Nepal Agriculture Research Council, Kathmandu, Nepal

Corresponding author: yuehui.ma@263.net
} 
India (Pardeshi et al., 2007; Arora et al., 2013; Singh et al., 2013). In contrast, information on phylogeography of Nepalese sheep mtDNA is scarce. Some investigation has been done on the morphological characteristics of Nepalese sheep breeds (Tsundoda et al., 1989; Neopane et al., 2008) and also on the genetic relationship between native sheep breeds based on blood protein typing and karyotyping (Dohge et al., 1989; Tsundoda et al., 1989), which revealed a relatively high genetic variability within the breeds. Nevertheless, genetic studies have indicated that morphological characteristics of livestock breeds may provide incomplete or misleading information on their evolutionary history (Lei et al., 2004). The variable structure of control region of mtDNA makes it possible to solve the problem of genetic polymorphism and origin, mainly because mtDNA displays a simple maternal inheritance without recombination and a relatively rapid evolution rate (Hiendleder et al., 1998b). Haplotype and nucleotide diversity of mtDNA are two important indices for assessing genetic polymorphism and differentiation (Pereira et al., 2006). Five maternal lineages (HapG A to E) have already been delineated in sheep mtDNA. Lineage HapG A was of Asian origin, HapG B predominated in Europe while HapG C, D and E originated in the Near East (Meadows et al., 2007). To date, no mtDNA sequence has been reported from any Nepalese sheep breed. The objective of this study was therefore to investigate the genetic diversity and structure of four Nepalese sheep breeds using mtDNA control region sequence variation.

\section{METHODOLOGY}

\section{Population sampling}

Blood samples from four Nepalese sheep breeds (Bhyanglung, Baruwal, Kage and Lampuchhre) were considered for the study. Samples were collected from sheep that were judged to be true to type with the phenotypic characteristics of that breed. The individuals selected had unrelated parents and grandparents based on the information provided by the owners and also cross-checked with their neighbours. A total of 111 individuals from different locations were sampled (Figure 1) and the blood was stored at $-40^{\circ} \mathrm{C}$ until further processing. The details of breeds, geographic regions and sample sizes are given in Table 1 .

Table 1. Four Nepalese sheep breeds from different geographic regions

\begin{tabular}{lll}
\hline Breed/population & Location & No. of samples sequenced \\
\hline Bhyanglung & Alpine region (Mustang, Jumla) & 29 \\
Baruwal & High hills (Rasuwa, Lamjung, Jumla) & 29 \\
Kage & Mid hills (Kathmandu, Lalitpur, & 30 \\
& Kavre) & \\
Lampuchhre & Low lands (Rupendehi, Siraha) & 23 \\
Total & & $\mathbf{1 1 1}$ \\
\hline
\end{tabular}

\section{DNA amplification and sequencing}

Total genomic DNA was extracted from whole blood using standard phenol/chloroform extraction protocol followed by ethanol precipitation (Sambrook et al., 2001). Eight hundred and seventeen base-pair (bp) long mtDNA control region of sheep was amplified using primers: 15388F (5'-GCC CCA CTA TCA ACA CCC AAA G-3') and CD-774R (5'-AAT GGG CGA TTT TAG ATG AGA TGG C-3') and sequenced using primers: CR018-for (5'- 
ATC ATT ATC AAC GAT AC-3') and CR653-rev (5'-GAA GAA AGA ACC AGA TGC CT3 ') following the procedure of Luo et al. (2005). Polymerase chain reaction (PCR) amplification was carried out in $50 \mu 1$ reaction mixtures. The PCR thermocycling condition included an initial denaturing step at $95^{\circ} \mathrm{C}$ for 5 min followed by 35 amplification cycles $\left(94^{\circ} \mathrm{C}\right.$ for $50 \mathrm{~s}, 57^{\circ} \mathrm{C}$ for $60 \mathrm{~s}$ and $72^{\circ} \mathrm{C}$ for $60 \mathrm{~s}$ ) and a final extension at $72^{\circ} \mathrm{C}$ for $10 \mathrm{~min}$. Amplified mtDNA control region fragments were directly sequenced.

\section{Analysis of sequence data}

The raw sequencing profiles of mtDNA control region from each of the 111 sheep samples were manually edited using program Chromas version 2.23. Cleaned sequences were aligned using the Cluster $W$ algorithm included in program MEGA version 4.0 (Tamura et al., 2007) to identify different haplotypes. Ten sheep mtDNA control region reference sequences belonging to the five known haplogroups (Meadows et al., 2011) were also included in the analysis, to facilitate the recognition of haplogroup status of each individual (Table 2). A neighbour-joining $(N J)$ tree was constructed for identified haplotypes together with all reference sequences based on the Kimura 2-parameter model implemented in the program MEGA 4.0. All gaps in the sequences were completely excluded from analysis. The robustness of internal branches was estimated based on 1000 bootstrap replications Haplotype diversity (h) and nucleotide diversity $(\pi)(\mathrm{Nei}, 1987)$ for each sheep breed were also estimated using program DnaSP version 4.10 (Rozas et al., 2003).

Table 2. Reference sequences for different haplogroups of sheep mtDNA (HapG A to E) (Meadows et al., 2011)

\begin{tabular}{ll}
\hline HapG & GenBank accession no. \\
\hline HapG A & HM236174.1, HM236175.1 \\
HapG B & HM236176.1, HM236177.1 \\
HapG C & HM236178.1, HM236179.1 \\
HapG D & HM236180.1, HM236181.1 \\
HapG E & HM236182.1, HM236183.1 \\
\hline
\end{tabular}

\section{RESULTS AND DISCUSSION}

\section{Sequence variation}

The mtDNA control region sequences from 111 Nepalese sheep samples sequenced in this study had four one-nucleotide insertions/deletions (indels), all involving thymine nucleotide. Except these minor indels, the observed length variations in these fragments were caused by different copy numbers of a 76 bp tandem repeat (5'-CGT ATA TTA GTA TTA ATG TAA TAT AGA CAT TAT ATG TAT AAA GTA CAT TAA ATG ATT TAC CCC ATG CAT ATA AGC A-3'). Most of the Nepalese sheep mtDNA control region sequences $(96.4 \%$; 107/111) had four tandem repeats whereas only four sequences (3.6\%; two from Baruwal and two from Kage) carried three tandem repeats and latter were excluded from further analysis. The remaining 107 sequences had 776 to 779 valid nucleotides excluding the two PCR primers. They were highly polymorphic with 132 variable sites, of which 36 were singleton variable sites (polymorphic sites appearing in only one animal) (27.3\%) and 96 were parsimony informative sites (which appear in more than one animal) (72.7\%). Out of total variable sites, 128 variants were transitions and four variants were transversions. 


\section{Haplogroup identification and phylogenetic analysis}

Sixty four haplotypes were identified from 107 mtDNA control region sequences of the four Nepalese sheep breeds (Table 3 and Figure 2). More haplotype variation in mtDNA implies that more females than males have been used for breeding over time. This may be reflective of maternal inheritance as the selection for indigenous breeds is mostly male-oriented. This conclusion is also supported by the occurrence of high number of singletons in Nepalese sheep mtDNA sequences, suggesting the contribution from a large number of females carrying highly divergent mtDNA sequences (Hassan et al., 2009).

Table 3. Haplotypes and their distribution in the four Nepalese sheep breeds

\begin{tabular}{|c|c|c|c|c|c|c|}
\hline \multirow[b]{2}{*}{ Haplotype } & \multirow{2}{*}{$\begin{array}{l}\text { Haplogrou } \\
\text { p }\end{array}$} & \multirow{2}{*}{$\begin{array}{l}\text { Frequenc } \\
\mathbf{y}\end{array}$} & \multicolumn{4}{|c|}{ Breed } \\
\hline & & & $\begin{array}{l}\text { Bhyanglun } \\
\text { g }\end{array}$ & Baruwal & Kage & $\begin{array}{l}\text { Lampuchhr } \\
\text { e }\end{array}$ \\
\hline Hap_1 & $\mathrm{A}$ & 5 & & 5 & & \\
\hline Hap_2 & & 7 & & 7 & & \\
\hline Hap_3 & & 3 & & 3 & & \\
\hline Hap_4 & & 1 & & 1 & & \\
\hline Hap_5 & & 2 & & 2 & & \\
\hline Hap_6 & & 1 & & 1 & & \\
\hline Hap_7 & & 1 & & 1 & & \\
\hline Hap_8 & & 1 & & 1 & & \\
\hline Hap_9 & & 1 & 1 & & & \\
\hline Hap_10 & & 1 & 1 & & & \\
\hline Hap_11 & & 1 & 1 & & & \\
\hline Hap_12 & & 4 & 4 & & & \\
\hline Hap_13 & & 2 & 2 & & & \\
\hline Hap_14 & & 2 & 2 & & & \\
\hline Hap_15 & & 2 & 2 & & & \\
\hline Hap_16 & & 2 & 2 & & & \\
\hline Hap_17 & & 1 & 1 & & & \\
\hline Hap_18 & & 1 & 1 & & & \\
\hline Hap_19 & & 2 & 2 & & & \\
\hline Hap_20 & & 5 & & & 5 & \\
\hline Hap_21 & & 1 & & & 1 & \\
\hline Hap_22 & & 1 & & & 1 & \\
\hline Hap_23 & & 1 & & & 1 & \\
\hline Hap_24 & & 1 & & & 1 & \\
\hline Hap_25 & & 3 & & & 3 & \\
\hline Hap_26 & & 1 & & & 1 & \\
\hline Hap_27 & & 1 & & & 1 & \\
\hline Hap_28 & & 1 & & & 1 & \\
\hline Hap_29 & & 1 & & & 1 & \\
\hline Hap_30 & & 1 & & & 1 & \\
\hline Hap_31 & & 1 & & & 1 & \\
\hline Hap_32 & & 2 & & & & 2 \\
\hline Hap_33 & & 2 & & & & 2 \\
\hline Hap_34 & & 1 & & & & 1 \\
\hline Hap_35 & & 2 & & & & 2 \\
\hline
\end{tabular}




\begin{tabular}{|c|c|c|c|c|c|c|}
\hline Hap_36 & & 1 & & & & 1 \\
\hline Hap_37 & & 1 & & & & 1 \\
\hline Hap_38 & & 1 & & & & 1 \\
\hline Hap_39 & & 4 & & & & 4 \\
\hline Hap_40 & & 1 & & & & 1 \\
\hline Hap_41 & & 1 & & & & 1 \\
\hline Hap_42 & & 4 & & & & 4 \\
\hline Hap_43 & & 1 & & & & 1 \\
\hline Hap_44 & & 1 & & & & 1 \\
\hline Hap_45 & B & 4 & & 4 & & \\
\hline Hap_46 & & 1 & & 1 & & \\
\hline Hap_47 & & 2 & 2 & & & \\
\hline Hap_48 & & 1 & 1 & & & \\
\hline Hap_49 & & 1 & 1 & & & \\
\hline Hap_50 & & 1 & 1 & & & \\
\hline Hap_51 & & 1 & & & 1 & \\
\hline Hap_52 & & 1 & & & 1 & \\
\hline Hap_53 & & 2 & & & 2 & \\
\hline Hap_54 & & 1 & & & & 1 \\
\hline Hap_55 & $\mathrm{C}$ & 1 & & 1 & & \\
\hline Hap_56 & & 1 & 1 & & & \\
\hline Hap_57 & & 1 & 1 & & & \\
\hline Hap_58 & & 1 & 1 & & & \\
\hline Hap_59 & & 1 & 1 & & & \\
\hline Hap_60 & & 1 & 1 & & & \\
\hline Hap_61 & & 2 & & & 2 & \\
\hline Hap_62 & & 1 & & & 1 & \\
\hline Hap_63 & & 2 & & & 2 & \\
\hline Hap_64 & & 1 & & & 1 & \\
\hline
\end{tabular}

No haplotype was shared between breeds, suggesting that a high level of genetic diversity was present within each of these breeds. This unique pattern of haplotype distribution may also be attributed to total reproductive isolation due to harsh geographical structure of the country and unique husbandry practices (migratory farming system) in the alpine region and high hills of the country (Gorkhali et al., 2006), that allow farmers to select animals with unique phenotypic characters associated with adaptability to different ecological conditions.

Using already identified (Meadows et al., 2011) sheep mtDNA haplogroup reference sequences, three haplogroups (A, B and C) were identified among all indigenous Nepalese sheep (Figure 1 and Figure 2) with 44, 10 and 10 haplotypes, respectively. Among them, haplogroup A was predominant (68.8\%) followed by haplogroups B (15.6\%) and C (15.6\%) (Tables 3 and 4). Except Lampuchhre, which had only haplogroups A and B, other three breeds possessed all three haplogroups (A, B and C). There was no specific haplogroup distribution pattern in breeds or different ecological regions. Haplogroup $\mathrm{C}$ sequences, which were first identified in Chinese sheep (Guo et al., 2005; Luo et al., 2005) and also detected late at low frequency in Middle Eastern and European sheep breeds (Pedrosa et al., 2005, 2007; Pereira et al., 2006; Tapio et al., 2006; Oner et al., 2013), were found in the three breeds distributed in the hills. This result suggested a probable gene flow from northeast to southwest but not reach the low lands of Nepal. Similar results were also observed in Indian 
sheep, in which haplogroups A and B were predominant in most of the breeds whereas haplogroup $\mathrm{C}$ was at very low frequency $(<1 \%)$ and only present in two breeds of

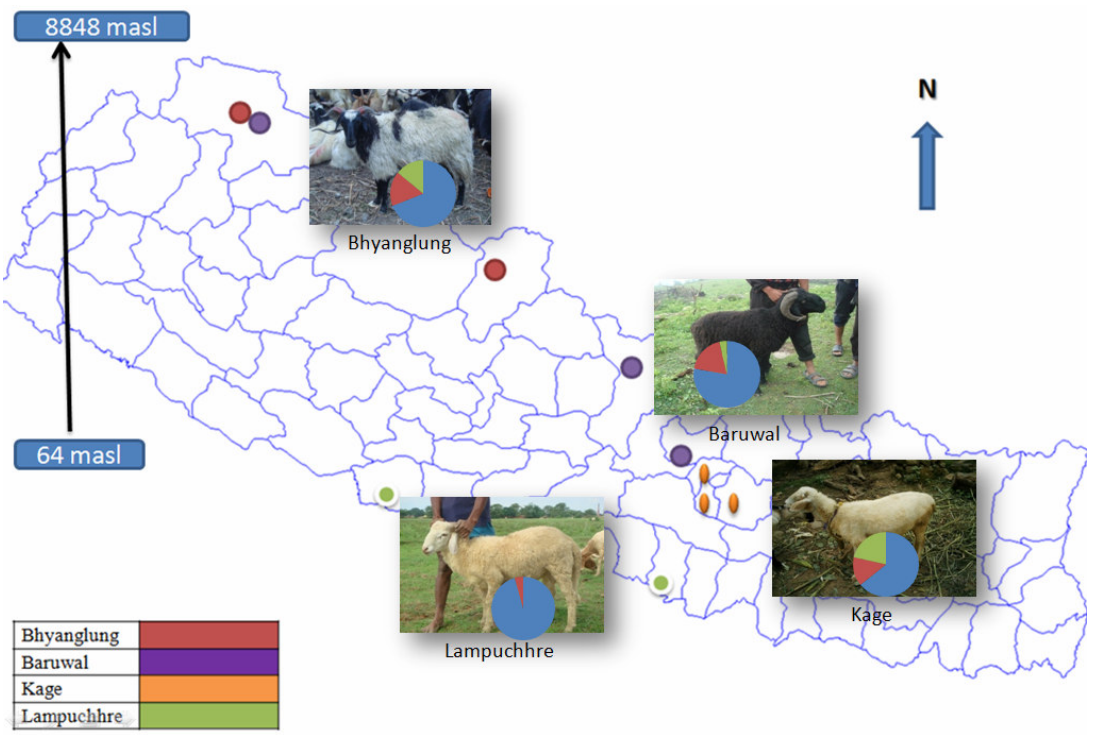

Fig. 1. Geographical distribution of samples and of the three mtDNA haplogroups A, $B$ and $C$ in Nepalese sheep breeds. Pie charts show the distribution of different haplogroups: HapG A (blue), HapG B (red) and HapG C (green)

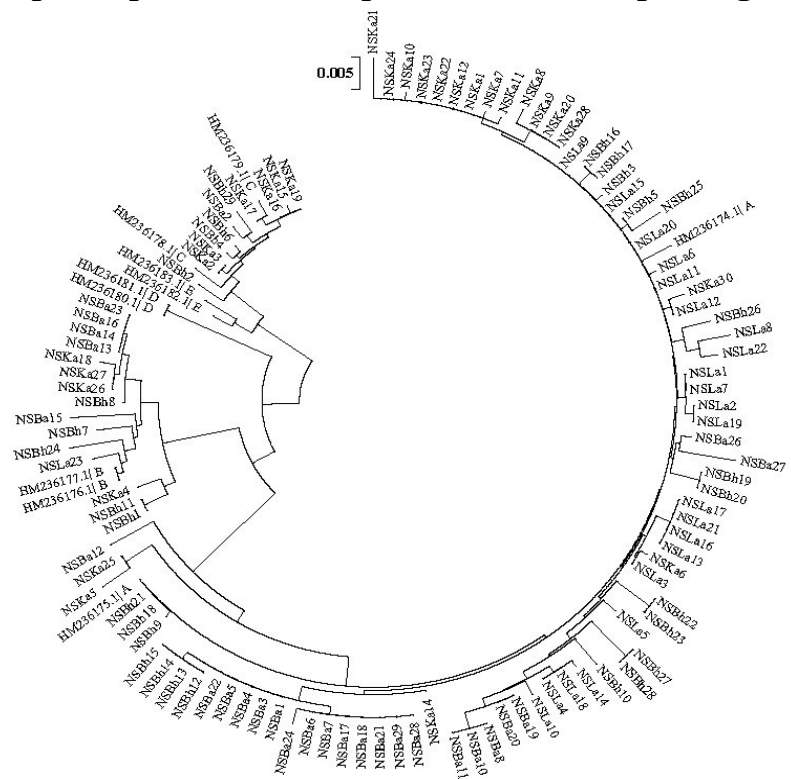

Fig. 2. The neighbor-joining phylogenetic tree constructed for 107 Nepalese sheep mtDNA sequences together with the 10 reference sequences belonging to the five known mtDNA control region haplogroups (A to E). All three major branches for lineages $\mathrm{A}, \mathrm{B}$ and $\mathrm{C}$ were supported by $>99 \%$ bootstrap replications 
north-western India (Pardeshi et al., 2007; Arora et al., 2013; Singh et al., 2013). Nepalese sheep also showed a weak population sub-structuring as observed based on the distribution of three mtDNA haplogroups, which could have resulted from ancient trading between the neighboring countries and free borders between the adjacent vicinities (Gorkhali et al., 2014).

\section{Genetic diversity}

The genetic diversity estimated on the basis of mtDNA control region sequences was similar among the four Nepalese sheep breeds. Number of haplotypes found in each breed ranged from 11 to 20 depending on the number of samples. The haplotype diversity ranged between 0.883 and 0.970 while nucleotide diversity ranged from 0.009 to 0.029 (Table 4). These observations were comparable with other sheep breeds/populations in the region (Chen et al., 2006; Pardeshi et al., 2007; Sulaiman et al., 2011; Arora et al., 2013; Singh et al,, 2013).

Table 4. Diversity and distribution of mtDNA haplogroups in Nepalese sheep breeds

\begin{tabular}{|c|c|c|c|c|c|c|}
\hline \multirow[t]{2}{*}{$\begin{array}{l}\text { Breed/ } \\
\text { population }\end{array}$} & \multirow[t]{2}{*}{$\begin{array}{l}\text { No. of } \\
\text { haplotypes }\end{array}$} & \multicolumn{3}{|c|}{ Haplogroups } & \multirow{2}{*}{$\begin{array}{l}\text { Haplotype } \\
\text { diversity } \\
(h \pm \text { SD) }\end{array}$} & \multirow{2}{*}{$\begin{array}{l}\text { Nucleotide } \\
\text { diversity } \\
(\pi \pm \text { SD })\end{array}$} \\
\hline & & $\mathbf{A}$ & $\mathbf{B}$ & $\mathbf{C}$ & & \\
\hline Bhyanglung & 20 & 19 & 5 & 5 & $0.970 \pm 0.017$ & $0.029 \pm 0.004$ \\
\hline Baruwal & 11 & 21 & 5 & 1 & $0.883 \pm 0.036$ & $0.022 \pm 0.004$ \\
\hline Kage & 19 & 18 & 4 & 6 & $0.958 \pm 0.024$ & $0.029 \pm 0.004$ \\
\hline Lampuchhre & 14 & 22 & 1 & & $0.941 \pm 0.030$ & $0.009 \pm 0.003$ \\
\hline Total & 64 & 80 & 15 & 12 & $0.985 \pm 0.004$ & $0.025 \pm 0.002$ \\
\hline
\end{tabular}

Overall haplotype diversity is high in Nepalese sheep. The high level of intra-population diversity and the weak geographical sub-structuring suggest that all three geographically independent domestication events for mtDNA HapG A, B and C have contributed to the genetic diversity of Nepalese sheep. Furthermore, this can be attributable to strong gene flow induced by historical human movements.

In general, the haplogroup prevalence in present study is consistent with the previous studies on domestic sheep breeds in Asia (Luo et al., 2005; Chen et al., 2006; Pardeshi et al., 2007; Wang et al., 2007; Zhao et al., 2011; Arora et al., 2013; Singh et al., 2013). Since haplogroup A is most predominant in Asia, it is difficult to understand the direction of its gene flow. In case of haplogroup $\mathrm{C}$, the gene flow from China towards India via Nepal can be an acceptable explanation as the gene flow of haplogroup $\mathrm{C}$ was from northeast towards southwest in the hilly areas but not to the low lands of Nepal.

\section{CONCLUSIONS}

Nepalese sheep revealed extensive and high mtDNA haplotype diversity. Haplogroups A to C were present in all the breeds found in low to high hills of the country except for Lampuchhre breed in low lands. The results also unveiled the origin of haplogroup $C$ with a unique geographic distribution pattern, indicating its gene flow from China towards India via Nepal. Hence, it can be concluded that all indigenous Nepalese sheep breeds have isolated 
breeding paths. Lack of crossbreeding among breeds is unique and important for the utilization and conservation of Nepalese sheep genetic resources.

\section{REFERENCES}

Arora, R., Yadav, H. and Mishra, B. (2013). Mitochondrial DNA diversity in Indian sheep. Livest. Sci., 153(1), 50 - 55.

Chen, S.Y., Duan, Z.Y., Sha, T., Xiangyu, J., Wu, S.F. and Zhang, Y.P. (2006). Origin, genetic diversity, and population structure of Chinese domestic sheep. Gene, 376(2), 216 223.

Dohge, K., Tsunoda, K., Nishida, T. and Rajbhandary, H.B. (1989). Karyotype analysis of the native sheep in Nepal. In: Morphological and Genetical Studies on the Native Domestic Animals and Their Wild Forms in Nepal. Faculty of Agriculture, The University of Tokyo, Japan, pp. 77 - 81.

Gorkhali, N.A., Rasali, D.P. and Rana, R.S. (2006). Study on the performance of the Broder Leicester $x$ Baruwal crosses and Baruwal sheep in the migratory management system of western hills of Nepal. Proceeding of the 6th National Workshop on Livestock and Fisheries Research, Kathmandu, Nepal, pp. 25 - 28.

Gorkhali, N.A., Shrestha, B., Ma Y.H. and Han J.L. (2014). Mitochondrial DNA diversity in Nepalese indigenous goats (Capra hirus). Proceeding of the 34th Conference of International Society of Animal Genetics (ISAG), Xi'an, Shaanxi, China, pp. 110 - 111.

Guo, J., Du, L.X., Ma, Y.H., Guan, W.J., Li, H.B., Zhao, Q.J., Li, X. and Rao, S.Q. (2005). A novel maternal lineage revealed in sheep (Ovis aries). Anim. Genet., 36(4), 331 - 336.

Hassan, A.A., El Nahas, S.M., Kumar, S., Godithala, P.S. and Roushdy, Kh. (2009). Mitochondrial D-loop nucleotide sequences of Egyptian river buffalo: variation and phylogeny studies. Livest. Sci., 125, 37 - 42.

Hiendleder, S., Lewalski, H., Wassmuth, R. and Janke, A. (1998a). The complete mitochondrial DNA sequence of the domestic sheep (Ovis aries) and comparison with the other major ovine haplotype. J. Mol. Evol., 47(4), 441 - 448.

Hiendleder, S., Mainz, K., Plante, Y. and Lewalski, H. (1998b). Analysis of mitochondrial DNA indicates that domestic sheep are derived from two different ancestral maternal sources: no evidence for contributions from urial and argali sheep. J. Hered., 89(2), 113 - 120.

Hiendleder, S., Kaupe, B., Wassmuth, R. and Janke, A. (2002). Molecular analysis of wild and domestic sheep questions current nomenclature and provides evidence for domestication from two different subspecies. Proc. Biol. Sci., 269(1494), 893 - 904.

Lei, X., Chen, Y., Chen, H., Yuan, Z., Xu, T., Guo, M., Lei, C. and Sun, W. (2004). Microsatellite markers on genetic relationship of six Chinese indigenous sheep breeds. Ani. Biotech. Bul., 9, 1 - 7.

Luo, Y.Z., Cheng, S.R., Lkhagva, B., Badamdorji, D., Hanotte, O. and Han J.L. (2005). 
Origin and genetic diversity of Mongolian and Chinese sheep using mitochondrial DNA Dloop sequences. Acta Genetica Sinica, 32(12), 1256 - 1265.

Meadows, J., Li, K., Kantanen, J., Tapio, M., Sipos, W., Pardeshi, V., Gupta, V., Calvo, J., Whan, V. and Norris, B. (2005). Mitochondrial sequence reveals high levels of gene flow between breeds of domestic sheep from Asia and Europe. J. Hered., 96(5), 494 - 501.

Meadows, J.R., Cemal, I., Karaca, O., Gootwine, E. and Kijas, J.W. (2007). Five ovine mitochondrial lineages identified from sheep breeds of the near East. Genetics, 175(3), 1371 -1379 .

Meadows, J.R., Hiendleder, S. and Kijas, J.W. (2011). Haplogroup relationships between domestic and wild sheep resolved using a mitogenome panel. Heredity (Edinb), 106(4), 700 706.

Nei, M. (1987). Molecular Evolutionary Genetics. New York: Columbia University Press.

Neopane, S.P., Gorkhali, N.A. and Pokharel, P.K. (2008). Indigenous sheep of Nepal. Nepal Agriculture Research Council (NARC), Khumaltar, Lalitpur, P.O. Box 1950, Kathmandu, Nepal.

Oner, Y., Calvo, J.H. and Elmaci, C. (2013). Investigation of the genetic diversity among native Turkish sheep breeds using mtDNA polymorphisms. Trop. Anim. Health and Prod., 45(4), 947 - 951.

Pardeshi, V., Kadoo, N., Sainani, M., Meadows, J., Kijas, J. and Gupta, V. (2007). Mitochondrial haplotypes reveal a strong genetic structure for three Indian sheep breeds. Anim. Genet., 38(5), 460 - 466.

Pedrosa, S., Uzun, M., Arranz, J-J., Gutiérrez-Gil, B., San Primitivo, F. and Bayón, Y. (2005). Evidence of three maternal lineages in near eastern sheep supporting multiple domestication events. Proc. Biol. Sci., 272(1577), 2211 - 2217.

Pedrosa, S., Arranz, J-J., Brito, N., Molina, A., San Primitivo, F. and Bayón, Y. (2007). Mitochondrial diversity and the origin of Iberian sheep. Genet. Select. Evol., 39(1), 91 - 103.

Pereira, F., Davis, S.J., Pereira, L., McEvoy, B., Bradley, D.G. and Amorim, A. (2006). Genetic signatures of a Mediterranean influence in Iberian Peninsula sheep husbandry. Mol. Biol. Evol., 23(7), 1420 - 1426.

Rozas, J., Sanchez-DelBarrio, J.C., Messeguer, X. and Rozas, R. (2003). DnaSP, DNA polymorphism analyses by the coalescent and other methods. Bioinformatics, 19, 2496 2497.

Sambrook, J., Fritsch, E.F. and Maniatis, T. (2001). Molecular Cloning: A Laboratory Manual, $3^{\text {rd }}$ ed. Cold Spring Harbor Laboratory Press. Cold Spring Harbor, New York.

Singh, S., Kumar, Jr. S., Kolte, A.P. and Kumar, S. (2013). Extensive variation and substructuring in lineage A mtDNA in Indian sheep: genetic evidence for domestication of sheep in India. PLoS ONE, 8(11), e77858. 
Sulaiman, Y., Wu, C. and Zhao, C. (2011). Phylogeny of 19 indigenous sheep populations in northwestern China inferred from mitochondrial DNA control region. Asian J. Anim. Vet. Adv., 6(1), 71 - 79.

Tamura, K., Peterson, D., Peterson, N., Stecher, G., Nei, M. and Kumar, S. (2011). MEGA5: molecular evolutionary genetics analysis using maximum likelihood, evolutionary distance, and maximum parsimony methods. Mol. Biol. Evol., 28(10), 2731 - 2739.

Tapio, M., Marzanov, N., Ozerov, M., Ćinkulov, M., Gonzarenko, G., Kiselyova. T., Murawski, M., Viinalass, H. and Kantanen, J. (2006). Sheep mitochondrial DNA variation in European, Caucasian, and Central Asian areas. Mol. Biol. Evol., 23(9), 1776 - 1783.

Tsunoda, K., Yamamoto, Y., Namikawa, T., Shotake, T., Amano, T., Maeda, Y., Nishida, T. and Rajbhandary, H.B. (1989). Morphological characteristics and genetic variability of the native sheep of Nepal. In: Morphological and Genetical Studies on the Native Domestic Animals and Their Wild Forms in Nepal. Faculty of Agriculture. The University of Tokyo, Japan. pp. 49 - 76.

Wang, X., Ma. Y., Chen, H. and Guan, W. (2007). Genetic and phylogenetic studies of Chinese native sheep breeds (Ovis aries) based on mtDNA D-loop sequences. Small Ruminant Res., 72(2), 232 - 236.

Zhao, Y., Zhao, E., Zhang, N. and Duan, C. (2011). Mitochondrial DNA diversity, origin, and phylogenic relationships of three Chinese large-fat-tailed sheep breeds. Trop. Anim. Health and Prod., 43(7), 1405 - 1410. 